\title{
The relationship between pain, analgesics and survival in patients with advanced cancer; a secondary data analysis of the international European palliative care Cancer symptom study.
}

\author{
Jason W Boland ${ }^{1}$ (1) $\cdot$ Victoria Allgar $^{2}$ • Elaine G Boland ${ }^{3} \cdot$ Mike I Bennett $^{4} \cdot$ Stein Kaasa ${ }^{5,6,7}$. \\ Marianne Jensen Hjermstad ${ }^{5,6,7} \cdot$ Miriam Johnson $^{1}$
}

Received: 13 August 2019 / Accepted: 18 November 2019/Published online: 21 December 2019

(C) The Author(s) 2019

\begin{abstract}
Purpose Opioids reduce cancer-related pain but an association with shorter survival is variably reported. Aim: To investigate the relationship between pain, analgesics, cancer and survival within the European Palliative Care Cancer Symptom (EPCCS) study to help inform clinical decision making.

Methods Secondary analysis of the international prospective, longitudinal EPCCS study which included 1739 adults with advanced, incurable cancer receiving palliative care. In this secondary analysis, for all participants with date of death or last follow up, a multilevel Weibull survival analysis examined whether pain, analgesics, and other relevant variables are associated with time to death.

Results Date of death or last follow-up was available for 1404 patients (mean age 65.7 [SD:12.3];men 50\%). Secondary analysis of this group showed the mean survival from baseline was 46.5 (SD:1.5) weeks (95\% CI:43.6-49.3). Pain was reported by 76\%; $60 \%$ were taking opioids, $51 \%$ non-opioid analgesics and $24 \%$ co-analgesics. Opioid-use was associated with decreased survival in the multivariable model ( $\mathrm{HR}=1.59$ (95\% CI:1.38-1.84), $p<0.001)$. An exploratory subgroup analysis of those with Creactive protein (CRP) measures $(n=219)$ indicated higher CRP was associated with poorer survival $(p=0.001)$. In this model, the strength of relationship between survival and opioid-use weakened $(p=0.029)$.

Conclusion Opioid-use and survival were associated; this relationship weakened in a small sensitivity-testing subgroup analysis adjusting for CRP. Thus, the observed relationship between survival and opioid-use may partly be due to tumour-related inflammation. Larger studies, measuring disease activity, are needed to confirm this finding to more accurately judge the benefits and risks of opioids in advanced progressive disease.
\end{abstract}

Keywords Neoplasms $\cdot$ Pain $\cdot$ Analgesics $\cdot$ Opioids $\cdot$ Survival

Electronic supplementary material The online version of this article (https://doi.org/10.1007/s00228-019-02801-2) contains supplementary material, which is available to authorized users.

Jason W Boland

Jason.Boland@hyms.ac.uk

1 Wolfson Centre for Palliative Care Research, Hull York Medical School, University of Hull, Hull, UK

2 Hull York Medical School, University of York, York, UK

3 Hull University Teaching Hospitals NHS Trust, Cottingham, UK

4 University of Leeds, Leeds Institute of Health Sciences, School of Medicine, Leeds, UK

5 Regional Advisory Unit in Palliative Care, Department of Oncology, Oslo University Hospital, Oslo, Norway

6 European Palliative Care Research Centre (PRC), Oslo University Hospital and Institute of Clinical Medicine, Oslo, Norway

7 Department of Oncology, University of Oslo, Oslo, Norway

\section{Introduction}

Pain is common in patients with advanced cancer. [1] Pain might be associated with a poorer prognosis, but the evidence is mixed. [2-6] Opioids, used to reduce pain, [7] might reduce immunity and survival, which might limit their use and increase suffering. [8-13] A systematic review showed that, although findings from individual studies were variable, opioids tended not to affect survival in the last days to weeks of life, but there was a possible association with shorter survival with longer term opioid-use. [14] These were mostly poor quality studies where the effect of opioids on survival was not the primary outcome. [14] The findings of this systematic review are supported by subsequent publications. [13, 15-17] Retrospective studies in patients in the last weeks of life have shown no statistically significant effect of opioids on survival. 
$[15,16]$ Prospective studies of patients with advanced cancer, in the last months of life, reported that patients taking opioids had a decreased survival compared to those not taking opioids. $[13,17]$ Thus, data to date report an association between opioids and survival in patients with advanced cancer only over months of administration.

Patients with aggressive or advanced disease are likely to have increased pain (triggering opioid prescribing) and shorter survival, confounding an independent association between opioids and survival. [6, 18-22] Symptomatic patients may also have worse Karnofsky Performance Status (KPS), (a measure of functional status), itself an independent predictor of survival. $[4,23-26]$ Long-term data exploring the association between pain, opioids and survival are limited, but it is vital to address this concern to more accurately judge the benefits and risks of opioids in advanced progressive disease. [8]

\section{Aim}

To investigate the relationship between pain, analgesic use and survival within the European Palliative Care Cancer Symptom (EPCCS) study. Our null hypothesis was that there is no relationship between these variables and survival.

\section{Methods}

\section{Study design}

Secondary analysis of participants in the prospective, longitudinal EPCCS cohort study. [27] Site recruitment, sites and patient eligibility criteria have been published. [27] The first clinical assessment (baseline) was performed upon study inclusion. Subsequent follow-up, either at hospital or by mail were monthly \pm one week, for at least six months if possible.

Eligible participants were consenting adults ( $\geq 18$ years) with advanced, incurable cancer enrolled in the centre's palliative care programme and able to comply with study procedures. Patients with severe cognitive impairment $(<4 / 8$ on the four-item version of the Mini-Mental State Examination) and thought to be imminently dying by the clinical team were excluded.

Demographic data (age, sex) and clinical data (type and stage of cancer at diagnosis) was collected at baseline. The baseline demographics have been published previously. [27] Data collected at each visit can be seen in Supplementary Table 1.

A retrospective recording of date of death was performed in February 2014, around 6 months after the last patient was included. Details of these have been published. [27]

\section{Statistical analyses}

The characteristics of the patients are presented for the baseline assessment using mean (sd), minimum and maximum or $\mathrm{n}$ $(\%)$.

Survival was determined from the date of first assessment to the date of death or date of last follow-up. [, 28] To examine the association between pain, analgesics and time to death a multilevel Weibull survival analysis model was used. Multilevel models consider repeated observations to be 'nested' within participants and accommodate data in which the number and timing of observations vary among participants. Hazard ratios and 95\% confidence intervals (CIs) are presented. Model fitting procedures were carried out using the mestreg command of STATA/ SE-14. To account for individual heterogeneity, a random effect at the individual level was included. The statistical significance of each covariate was tested with a t-test (estimate/standard error). Statistical significance was tested on the univariable analysis for each covariate and multivariable models. Models 1-3 explored the relationship between pain scores and use of each type of analgesic medication (non-opioid analgesics, opioids, co-analgesics) and the association with survival, adjusted for age, sex, stage and KPS. The interaction of pain and each type of analgesic medication was also explored. The full model (Model 4) included all three types of analgesic medication (non-opioid analgesics, opioids, co-analgesics) and pain, adjusted for age, gender, stage of cancer and KPS. Model 5 included, in addition to the variables in Model 4, Creactive protein (CRP), to explore the influence of systemic inflammation/disease activity on survival.

All analyses were undertaken on STATA SE (StataCorp.2015. Stata Statistical Software: Release-14. College Station, TX:StataCorp LP).

\section{Ethics}

Ethics approval was obtained at each EPCCS recruiting site. The study was performed according to the Declaration of Helsinki and was registered in the ClinicalTrials.gov database (No.NCT01362816). No further ethical approval was necessary for this secondary analysis of anonymised data [http://www.hra. nhs.uk].

\section{Results}

\section{Patient characteristics}

The original study included 1739 patients with baseline data (mean age 65.8 years (SD: 12.4) range 21-97; men 
Table 1 Descriptive characteristics at baseline

\begin{tabular}{|c|c|c|c|}
\hline & & $\begin{array}{l}\text { Total sample } \\
n=1739\end{array}$ & $\begin{array}{l}\text { Date of death or last follow-up } \\
n=1404\end{array}$ \\
\hline & & $\begin{array}{l}\text { Mean (sd) Min-Max (n) } \\
\text { or } n(\%)\end{array}$ & $\begin{array}{l}\text { Mean (sd) Min-Max (n) } \\
\text { or } n(\%)\end{array}$ \\
\hline Age & & 65.8 (12.4), 21-97 (1738) & 65.7 (12.3), 23-97 (1403) \\
\hline \multirow[t]{3}{*}{ Sex } & Female & $871(50 \%)$ & $696(50 \%)$ \\
\hline & Male & $866(50 \%)$ & $708(50 \%)$ \\
\hline & Missing & 2 & 2 \\
\hline \multirow[t]{3}{*}{ Stage } & Metastatic/disseminated & $1437(84 \%)$ & $1162(84 \%)$ \\
\hline & Local/locally advanced & $284(16 \%)$ & $229(16 \%)$ \\
\hline & Missing & 18 & 13 \\
\hline \multirow[t]{16}{*}{ Cancer type } & Cancer of the digestive organs & $528(31 \%)$ & $443(32 \%)$ \\
\hline & Cancer of the respiratory organs & $345(20 \%)$ & $292(21 \%)$ \\
\hline & Malignant bone tumours & $8(1 \%)$ & $8(1 \%)$ \\
\hline & Skin cancer inc. malignant melanoma & $37(2 \%)$ & $29(2 \%)$ \\
\hline & Malignant connective and soft tissue tumours & $40(2 \%)$ & $32(2 \%)$ \\
\hline & Breast cancer & $287(17 \%)$ & $212(15 \%)$ \\
\hline & Gynaecological cancer & $103(6 \%)$ & $77(6 \%)$ \\
\hline & Cancer of the male genital organs & $129(8 \%)$ & $99(7 \%)$ \\
\hline & Urinary cancer & $79(5 \%)$ & $67(5 \%)$ \\
\hline & Tumours of the CNS & $27(2 \%)$ & $25(2 \%)$ \\
\hline & Malignant endocrine tumours & $11(1 \%)$ & $11(1 \%)$ \\
\hline & $\begin{array}{l}\text { Secondary and ill-defined malignant tumours } \\
\text { and unspecified sites }\end{array}$ & $23(1 \%)$ & $20(1 \%)$ \\
\hline & Cancer of the head & $61(4 \%)$ & $40(3 \%)$ \\
\hline & Leukaemia's and lymphomas & $47(3 \%)$ & $39(3 \%)$ \\
\hline & Multiple primary cancers & $2(<1 \%)$ & $2(<1 \%)$ \\
\hline & Missing & 12 & 8 \\
\hline \multirow[t]{3}{*}{ Non-opioid analgesics } & Yes & $808(47 \%)$ & $701(51 \%)$ \\
\hline & No & $896(53 \%)$ & $678(49 \%)$ \\
\hline & Missing & 35 & 25 \\
\hline \multirow[t]{3}{*}{ Opioids } & Yes & $1012(59 \%)$ & $826(60 \%)$ \\
\hline & No & $694(41 \%)$ & $554(40 \%)$ \\
\hline & Missing & 33 & 24 \\
\hline \multirow[t]{3}{*}{ Co-analgesics } & Yes & $410(24 \%)$ & $332(24 \%)$ \\
\hline & No & $1279(76 \%)$ & $1033(76 \%)$ \\
\hline & Missing & 50 & 39 \\
\hline \multirow{5}{*}{$\begin{array}{l}\text { Brief Pain Inventory (BPI); } \\
\text { Average pain in the last } 24 \mathrm{~h}\end{array}$} & No pain & $434(26 \%)$ & $330(24 \%)$ \\
\hline & Mild & $563(33 \%)$ & $459(34 \%)$ \\
\hline & Moderate & $451(26 \%)$ & $378(28 \%)$ \\
\hline & Severe & $250(15 \%)$ & $197(14 \%)$ \\
\hline & Missing & 41 & 40 \\
\hline \multirow{6}{*}{$\begin{array}{l}\text { Edmonton Classification System for } \\
\text { Cancer Pain (ECS-CP); Mechanism } \\
\text { of Pain }\end{array}$} & No pain & $481(28 \%)$ & $381(28 \%)$ \\
\hline & Any nociceptive combination of visceral and/or & $868(51 \%)$ & $712(52 \%)$ \\
\hline & bone or soft tissue pain & $326(19 \%)$ & $256(19 \%)$ \\
\hline & Neuropathic pain syndrome with or without any & $24(2 \%)$ & $22(2 \%)$ \\
\hline & combination of nociceptive pain & 37 & 33 \\
\hline & Insufficient information to classify & & \\
\hline Karnofsky Performance Status (KPS) & & $67.0(16.5) 10-100(1724)$ & 66.8 (16.3) $10-100(1364)$ \\
\hline $\begin{array}{l}\text { C-reactive protein }(\mathrm{CRP}) \\
\quad(\text { subgroup } n=240)\end{array}$ & & $55.0(72.7), 0-379(240)$ & $58.5(74.4), 1-379(219)$ \\
\hline
\end{tabular}

$50 \%)$. The baseline characteristics are shown in Table 1. During the study, 1090 patients died (date of death missing for 25) and 339 were alive at the last followup. Information about vital status was missing for 310 patients, hence there are 1404 with a date of death or last follow-up date for the remaining analysis. Table 1 shows this group was comparable to the total sample on the key characteristics.

\section{Severity of pain and analgesic use}

\section{Baseline}

Pain was reported by $76 \%$ (Table 1). Table 2 shows that $60 \%$ of patients were taking opioids, $51 \%$ were taking non-opioid analgesics and $24 \%$ co-analgesics. There was a statistically significant association between the presence of pain and each 
Table 2 Brief Pain Inventory (BPI): Average pain in the last $24 \mathrm{~h}$ by type of analgesic medication at baseline

\begin{tabular}{|c|c|c|c|c|c|c|}
\hline \multirow[b]{2}{*}{ BPI: Average pain in the last $24 \mathrm{~h}$} & \multicolumn{2}{|c|}{ Non-opioid analgesics* } & \multicolumn{2}{|l|}{ Opioids* } & \multicolumn{2}{|c|}{ Co-analgesics* } \\
\hline & $\begin{array}{l}\text { Yes } \\
683(51 \%)\end{array}$ & $\begin{array}{l}\text { No } \\
658(49 \%)\end{array}$ & $\begin{array}{l}\text { Yes } \\
800(60 \%)\end{array}$ & $\begin{array}{l}\text { No } \\
542(40 \%)\end{array}$ & $\begin{array}{l}\text { Yes } \\
322(24 \%)\end{array}$ & $\begin{array}{l}\text { No } \\
1006(76 \%)\end{array}$ \\
\hline No pain & $95(29 \%)$ & $229(71 \%)$ & $87(27 \%)$ & $235(73 \%)$ & $32(10 \%)$ & $291(90 \%)$ \\
\hline Mild & $235(52 \%)$ & $218(48 \%)$ & $278(61 \%)$ & $176(39 \%)$ & $112(25 \%)$ & $336(75 \%)$ \\
\hline Moderate & $220(60 \%)$ & $149(40 \%)$ & $274(74 \%)$ & $97(26 \%)$ & $114(31 \%)$ & $251(69 \%)$ \\
\hline Severe & $133(68 \%)$ & $62(32 \%)$ & $161(83 \%)$ & $34(17 \%)$ & $64(33 \%)$ & $128(67 \%)$ \\
\hline
\end{tabular}

* Statistically significant $(p<0.001)$ difference between BPI: Average pain in the last $24 \mathrm{~h}$ and patients taking each type of analgesic medication at baseline

type of analgesic medication (Table 2). Patients were more likely to take analgesic medications with a more severe pain intensity $(p<0.001)$.

\section{The relationship between pain, analgesic use and survival}

The mean survival from baseline was 46.5 (1.5) weeks $(95 \%$ CI:43.6-49.3). From the last assessment, the mean survival was 38.8 (1.5) weeks (95\% CI:35.9-41.8).

Table 3 shows the univariable analysis. Increasing age, male gender and a higher KPS were associated with a decrease in the hazard of death $(\mathrm{p}<0.001)$.
There was a higher hazard of death, associated with moderate $(1.24(1.07,1.45), p=0.004)$ or severe $(1.28(1.05$, $1.55), p=0.013$ ) pain, compared to no pain. For specific pain classifications, compared with no pain, those with nociceptive pain had an increased hazard of death $(1.21$ (1.06, 1.38), $p=$ $0.005)$, but this relationship was not seen in those with neuropathic pain, either alone or in combination with nociceptive pain $(p=0.224)$. Opioid $(1.88(1.64,2.17), p<0.001)$ and coanalgesic use $(1.22(1.05,1.41), p=0.007)$ were associated with a higher hazard of death; non-opioid analgesic use ( $p=$ 0.142 ) was not. The survival curves for each type of analgesic medication, pain severity and pain mechanism illustrate these findings (Fig. 1).

Table 3 Univariable analysis for covariates and survival

\begin{tabular}{|c|c|c|}
\hline \multirow[t]{2}{*}{ Covariate } & \multicolumn{2}{|l|}{ Univariable } \\
\hline & Hazard $(95 \%$ CI) & $p$ value \\
\hline Age & $1.03(1.02,1.04)$ & $<0.001$ \\
\hline Gender (Male) & $1.96(1.60,2.40)$ & $<0.001$ \\
\hline \multicolumn{3}{|l|}{ Stage of disease } \\
\hline Local/locally advanced & 1.00 & \\
\hline Metastatic/disseminated & $1.03(0.82,1.30)$ & 0.790 \\
\hline Non-opioid analgesics (Yes) & $1.09(0.97,1.23)$ & 0.142 \\
\hline Opioids (Yes) & $1.88(1.64,2.17)$ & $<0.001$ \\
\hline Co-analgesics (Yes) & $1.22(1.05,1.41)$ & 0.007 \\
\hline \multicolumn{3}{|l|}{ Brief Pain Inventory (BPI); Average pain in the last $24 \mathrm{~h}$} \\
\hline \multicolumn{3}{|l|}{ No pain } \\
\hline Mild & 1.00 & \\
\hline Moderate & $1.08(0.94,1.24)$ & 0.264 \\
\hline Severe & $\begin{array}{l}1.24(1.07,1.45) \\
1.28(1.05,1.55)\end{array}$ & $\begin{array}{l}0.004 \\
0.013\end{array}$ \\
\hline \multicolumn{3}{|l|}{ Edmonton Classification System for Cancer Pain (ECS-CP): Mechanism of } \\
\hline Pain & 1.00 & \\
\hline No pain & $1.21(1.06,1.38)$ & 0.005 \\
\hline \multicolumn{3}{|l|}{ Any nociceptive combination of visceral and/or bone or soft tissue pain } \\
\hline Neuropathic pain syndrome with or without any combination of nociceptive pain & $1.11(0.93,1.34)$ & 0.224 \\
\hline Insufficient information to classify & $1.14(0.77,1.70)$ & 0.513 \\
\hline Karnofsky Performance Status (KPS) & $0.961(0.957,0.964)$ & $<0.001$ \\
\hline
\end{tabular}


Fig. 1 Survival curves (days) for use of each type of analgesic medication (non-opioid analgesics, opioids, co-analgesics), average severity of pain in the last $24 \mathrm{~h}$ Brief Pain Inventory (BPI) and pain mechanism $(p$-values are presented in Table 3)
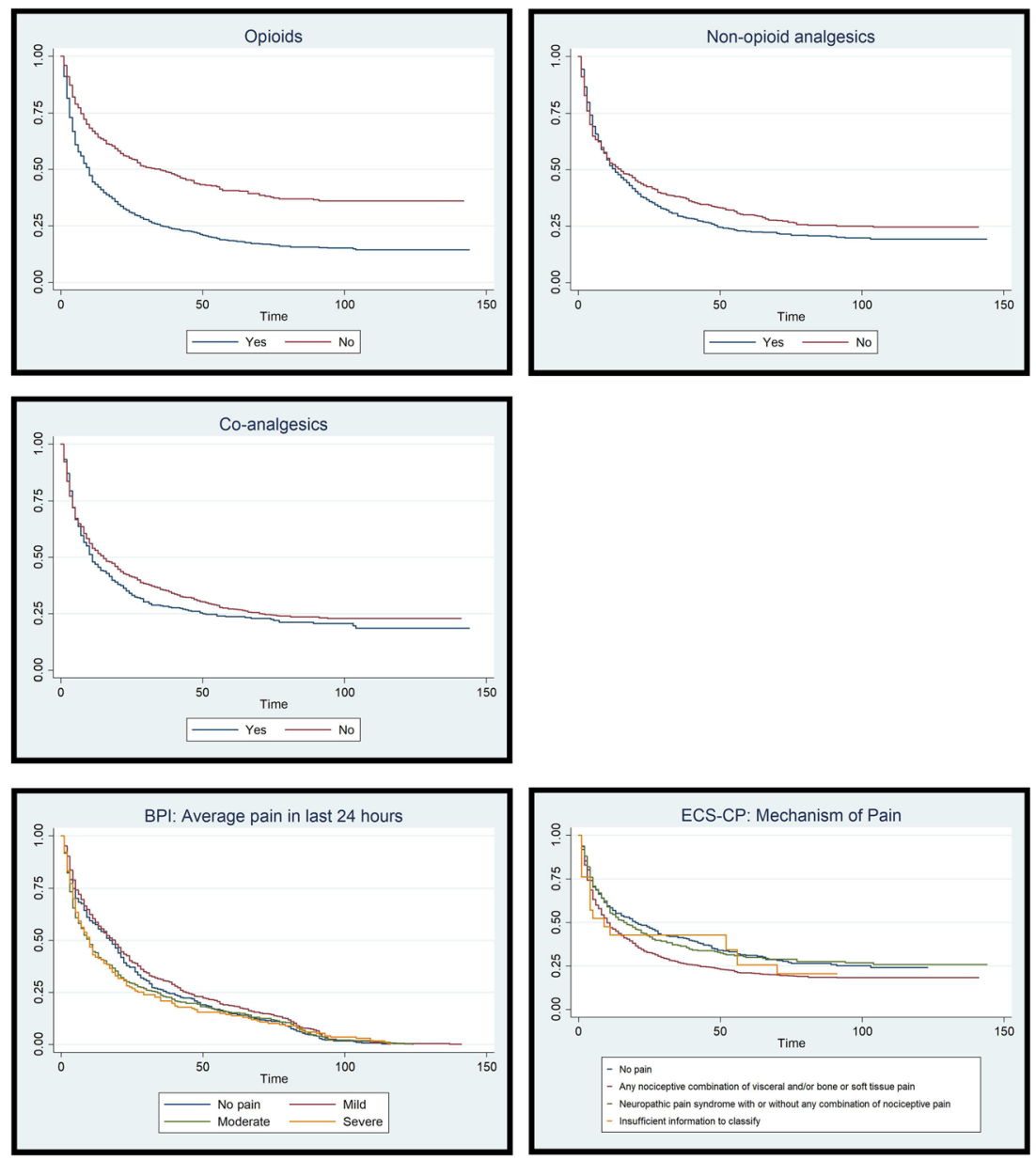

To explore the relationship with pain, analgesics and survival, multivariable models were undertaken for each analgesic group and BPI pain and the interaction (models 1-3; Table 4), adjusted for age and gender, stage of cancer and KPS. As there was a strong association with BPI pain $(p<$ 0.001), Edmonton Classification System for Cancer Pain (ECS-CP): Mechanism of pain was excluded in the models and BPI average pain in the last $24 \mathrm{~h}$ was used as the key variable for pain measurement.

Model 1 (Table 4) shows that opioid-use was statistically significant $(\mathrm{HR}=1.74$ (95\% CI:1.38-2.21), $\mathrm{p}<0.001)$ and Model 2 shows that co-analgesics use was statistically significant $(\mathrm{HR}=1.37$ (95\% CI:1.02-1.84), $p=0.034)$. Model 3 shows that non-opioid analgesics was not statistically significant $(p=0.250)$. In models $1-3$, the interaction between pain and analgesic use was not statistically significant, so was not included in the full model (Model 4; Table 4). Model 4 included each type of analgesic medication and pain, adjusted for age, gender, stage of cancer and KPS. In this model, only opioid-use was associated with an increased hazard of death ( $\mathrm{HR}=1.59$ (95\% CI:1.38-1.84), $p<0.001)$.
$\mathrm{C}$-reactive protein (CRP) was excluded from the main analysis above as data were only available at baseline in a small subgroup ( $n=219 ; 16 \%$ ) who had a date of death or last follow-up. An exploratory sensitivity analysis with a multivariable model including CRP (Table 4, Model 5) revealed CRP was statistically significantly related, with a higher hazard of death for a unit increase in CRP (Hazard ratio $=1.004(95 \%$ CI:1.002-1.006), $p=0.001$, Model 5). Only opioid-use remained statistically significant in this model, although the strength of relationship between decreased survival and opioid-use weakened $(\mathrm{HR}=1.38$ (95\% CI:1.03-1.85), $p=$ 0.029).

\section{Discussion}

Overall analysis of these secondary data from unselected adults with advanced, incurable cancer, treated in palliative care units, showed that the only independent association with poorer survival was opioids. Conclusions cannot be drawn regarding causality from these observational data and thus should be interpreted with caution. A subgroup 
Table 4 Multivariable analysis (hazard ratio $(95 \% \mathrm{CI})$ ) to investigate hazard of death $\dagger$

\begin{tabular}{|c|c|c|c|c|c|}
\hline & $\begin{array}{l}\text { Model 1: } \\
\text { Opioid, pain and } \\
\text { interaction }\end{array}$ & $\begin{array}{l}\text { Model 2: } \\
\text { Co-analgesic, pain } \\
\text { and interaction }\end{array}$ & $\begin{array}{l}\text { Model 3: } \\
\text { Non-opioid, pain } \\
\text { and interaction }\end{array}$ & $\begin{array}{l}\text { Model 4: } \\
\text { Each type of analgesic } \\
\text { medication and pain }\end{array}$ & $\begin{array}{l}\text { Model 5: } \\
\text { Each type of analgesic } \\
\text { medication, pain and CRP }\end{array}$ \\
\hline $\begin{array}{l}\text { Non-opioid analgesics } \\
\quad \text { (yes) }\end{array}$ & & & $1.14(0.91,1.42)$ & $1.06(0.94,1.19)$ & $1.15(0.90,1.47)$ \\
\hline Opioids (yes) & $\begin{array}{l}1.74(1.38 \\
2.21)^{* * *}\end{array}$ & & & $1.59(1.38,1.84)^{* * *}$ & $1.38(1.03,1.85)^{*}$ \\
\hline Co-analgesics (yes) & & $1.37(1.02,1.84)^{*}$ & & $1.00(0.86,1.15)$ & $0.88(0.62,1.24)$ \\
\hline \multicolumn{6}{|c|}{ BPI average pain in the last $24 \mathrm{~h}$} \\
\hline No pain & 1.00 & 1.00 & 1.00 & 1.00 & 1.00 \\
\hline Mild & $1.05(0.86,1.27)$ & $1.11(0.95,1.29)$ & $1.06(0.89,1.27)$ & $1.00(0.87,1.15)$ & $0.88(0.63,1.20)$ \\
\hline Moderate & $1.17(0.92,1.48)$ & $1.23(1.04,1.46)$ & $1.23(1.00,1.51)$ & $1.07(0.92,1.25)$ & $0.96(0.66,1.28)$ \\
\hline Severe & $1.02(0.67,1.55)$ & $1.26(1.00,1.59)$ & $1.21(0.91,1.62)$ & $1.05(0.86,1.28)$ & $1.02(0.64,1.63)$ \\
\hline \multicolumn{6}{|l|}{ Non-opioid x BPI } \\
\hline $\begin{array}{l}\text { Non-opioid (yes) *BPI } \\
\quad \text { (no pain) }\end{array}$ & & & 1.00 & & \\
\hline $\begin{array}{l}\text { Non-opioid (yes) *BPI } \\
\text { mild pain) }\end{array}$ & & & $0.96(0.74,1.24)$ & & \\
\hline $\begin{array}{l}\text { Non-opioid (yes) *BPI } \\
\text { (moderate pain) }\end{array}$ & & & $0.90(0.68,1.18)$ & & \\
\hline $\begin{array}{l}\text { Non-opioid (yes) } * \text { BPI } \\
\quad \text { (severe pain) }\end{array}$ & & & $0.91(0.63,1.31)$ & & \\
\hline \multicolumn{6}{|l|}{ Opioid x BPI } \\
\hline $\begin{array}{l}\text { Opioid (Yes) *BPI (no } \\
\text { pain) }\end{array}$ & 1.00 & & & & \\
\hline $\begin{array}{l}\text { Opioid (Yes) *BPI mild } \\
\text { pain) }\end{array}$ & $0.90(0.69,1.18)$ & & & & \\
\hline $\begin{array}{l}\text { Opioid (Yes) *BPI (mod- } \\
\text { erate pain) }\end{array}$ & $0.87(0.64,1.19)$ & & & & \\
\hline $\begin{array}{l}\text { Opioid (Yes) *BPI (severe } \\
\text { pain) }\end{array}$ & $0.99(0.61,1.60)$ & & & & \\
\hline \multicolumn{6}{|l|}{ Co-analgesics x BPI } \\
\hline $\begin{array}{l}\text { Co-analgesics (Yes) } \\
\text { *BPI (no pain) }\end{array}$ & & 1.00 & & & \\
\hline $\begin{array}{l}\text { Co-analgesics (Yes) } \\
\text { *BPI mild pain) }\end{array}$ & & $0.78(0.56,1.08)$ & & & \\
\hline $\begin{array}{l}\text { Co-analgesics (Yes) } \\
\text { *BPI (moderate pain) }\end{array}$ & & $0.77(0.55,1.09)$ & & & \\
\hline $\begin{array}{l}\text { Co-analgesics (Yes) } \\
\text { *BPI (severe pain) }\end{array}$ & & $0.72(0.47,1.08)$ & & & \\
\hline CRP & & & & & $1.004(1.002,1.006)^{* * *}$ \\
\hline
\end{tabular}

$\dagger$ All models adjusted for age, gender, stage and Karnofsky Performance Status (KPS), ${ }^{*} p<0.05, * * p<0.01, * * * \mathrm{p}<0.001$

$B P I$ Brief Pain Inventory, CRP C-reactive protein

analysis of those who had also had CRP measures showed that the strength of relationship with opioids reduced. This raises the hypothesis that the observed relationship between opioids and survival may be driven by both tumour-related factors (inflammatory response from disease activity) and treatment-related factors (opioids).

\section{Effect of demographics on survival}

There was an increased hazard of death $(1.96(1.60,2.40)$ for males compared to females; breast cancer had better survival than all other cancers. This is consistent with published literature. [29] This might be partly explained by some cancers in women being more amenable to treatment. [30] Older age was also associated with a shorter survival but the hazard ratio was marginal. Being older has been shown to correlate to decreased survival, but tumour site, type and stage of disease are also important. [4, 29-31] The relationship in our study might be weaker as they were a less well-mixed cancer population and mostly in the last year of life. Metastatic/ disseminated disease was not statistically associated with a shorter survival but a higher hazard ratio was observed for metastatic/disseminated, again consistent with published literature. [4, 29, 31] 


\section{Effect of opioids and pain on survival}

In the adjusted model, opioid-use was associated with an increased hazard of death; non-opioid, co-analgesics and severity of pain were not. Although this was adjusted for known variables (age, gender, stage of cancer and KPS), there are unknown confounders such as the pre-opioid pain score for patients on opioids at baseline, the clinical decision making, monitoring and compliance that surrounds opioid-use, opioid dose, type, or route of administration. The finding that opioiduse was associated with decreased survival in patients in the last months of life is supported by previous studies. $[13,17]$

Pain severity and opioid-use were not related (Table 2); opioids reduce pain, so opioid-use might be a bystander effect. $[6,32]$ In the univariable model, moderate and severe pain were associated with a decreased survival (Table 3); however, in the multivariable model the effect of opioids on survival dominates (Table 4). Some previous studies have shown an association between higher pain scores and a poorer prognosis, but the evidence is mixed. [2-6] The lack of association between pain and survival in this analysis might be because although opioids are triggered by pain, their subsequent use reduces pain and so in themselves confound the relationship between pain and survival; opioids have taken over as proxy for disease progression. Clinically, increased pain triggers opioid-use, opioids in turn reduce pain, as opioid dose increases this potentially displaces any subsequent independent effect of pain and survival. It is still the underlying pain that dictates opioid-use (even though intensity is reduced), and it's the underlying disease that dictates pain. There are many causes of cancer-related pain, the physical aspect being modulated by psycho-social-spiritual factors. [1, 7, 33] Physical pain related to the cancer may be due to both extent and the characteristics of the tumour; an aggressive inflammatory tumour may be more painful. [18-22, 34]

There was an increased hazard of death for nociceptive pain (combined with visceral and/or bone or soft tissue pain) compared to no pain, but no increased hazard for neuropathic pain syndrome with or without any combination of nociceptive pain compared to no pain. However, numbers of patients with neuropathic pain might have been too small (19\% vs $50 \%$ nociceptive pain) to detect an effect. Pain characterization was limited; one question from the ECS-CP on mechanism of pain on clinical assessment. [35] There are different causes for neuropathic pain in patients with cancer, some of these might not be associated with systemic inflammation and thus less impact on survival. [1]

\section{Effect of CRP on survival}

In the exploratory sensitivity analysis increasing CRP was associated with worse survival $(p<0.001)$ and the effect size for opioid was reduced. This suggests systemic inflammation might be an important confounder in the opioid-survival relationship. The effect size for CRP was small with wide confidence intervals in keeping with an exploratory analysis with a small sample $(n=219)$. However, the findings are consistent with the literature observing a relationship between higher CRP and worse prognosis. [26, 36, 37] Advanced disease does not fully explain survival, but tumour activity might be more important. $[18,19]$ Increased tumour activity might be a driver for systemic inflammation which could be associated with a shorter survival and be painful. [18, 19] This exploratory analysis suggested that that the opioid-survival relationship is likely modified by disease activity. This indicates that information on disease activity in needed in future studies.

\section{Limitations}

This study was not designed to assess the effect of opioids from initiation, with survival as the primary endpoint. [14] Multiple interacting factors influence survival such as tumour, type of analgesic medication and other treatment, or patient and clinician/service characteristics. Tumour related factors include the type, stage, location and aggressiveness of the cancer. There are insufficient numbers in this dataset to analyse by type and only a subgroup $(n=219)$ had CRP measurements. Patient characteristics include co-morbidities, the meaning of the pain, depression, coping, family, as well as compliance with medication. We have accounted for the variables for which we have sufficient data, but there are other confounders, which are either unknown, or for which the dataset is too small to support analysis. A larger prospective cohort is needed to address this limitation.

Although consecutive patients were recruited, those with cognitive impairment were excluded. There was limited information collected on analgesic medications. It is only known if patients were on opioids, non-opioid analgesics or co-analgesics. The opioid dose and type, doses or type of other analgesics, their titration, the clinical situation, monitoring, and how side effects were managed were not recorded. Thus, doseresponse relationships could not be determined. Cancer pain is often mixed nociceptive, neuropathic and inflammatory, and clinical, radiological and neuroanatomical description to accurately determine the mechanism of pain was beyond the scope of this study. [35] There might be a predominant element but in the collected data nociceptive pain included visceral and/or bone or soft tissue pain and these might have neuropathic elements. Information about CRP was only on a small subgroup of patients, this limits the inferences that can be made about tumour activity and systemic inflammation.

\section{Implications for clinical practice}

This study raises a preliminary hypothesis that the observed association between opioids and survival may be partly driven 
Fig. 2 Associations between cancer, inflammation, pain, opioids and survival Pain is common in patients with advanced cancer, some of this is via inflammation caused by the immune response to cancer. [1] Opioids are prescribed for pain. [7] Survival is dependent on multiple factors, including the underlying cancer, the systemic inflammatory response and opioids. [8-12, 14, 18-22] Pain might also affect survival, [2-5] but this is offset by opioid-use in this analysis.

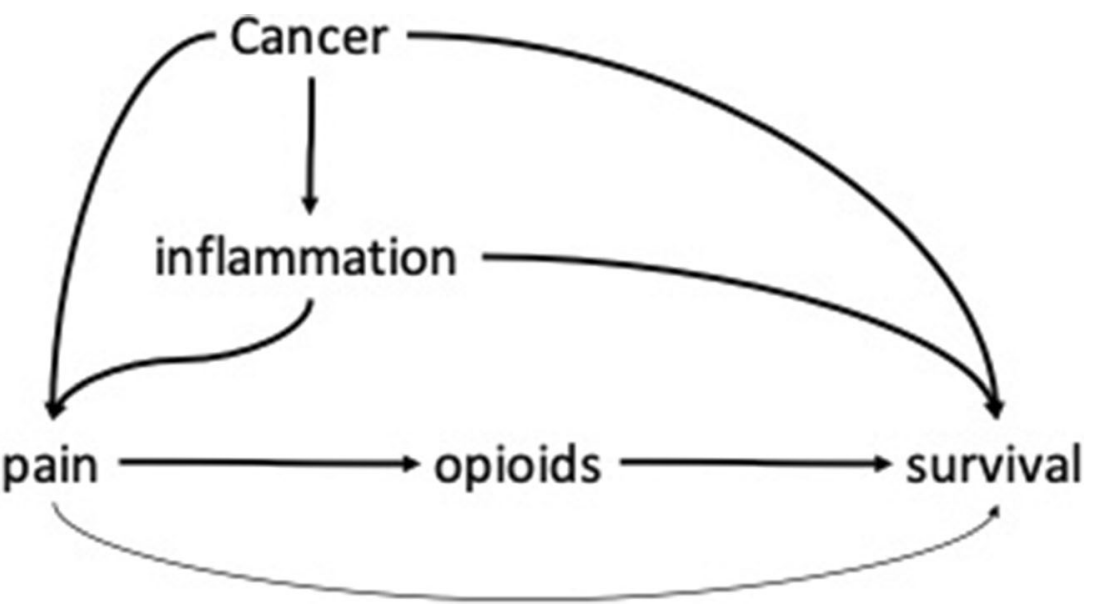

by tumour-related inflammation; causality cannot be attributed. In clinical practice, patients cannot be left in pain, it is thus important that patients who have cancer-related pain are given effective analgesia and monitored appropriately to minimize potential harm. Furthermore, epidemiological data from UK and Canada suggest that only $42-48 \%$ of patients that die from cancer receive an opioid, and median treatment duration is around 9 weeks. [38-40] These studies suggest that undertreatment with opioids rather than over-treatment might be the more important clinical challenge. Opioid-use is likely to reflect more aggressive painful disease and is thus a "biomarker" of a poor outcome, patients still need to be monitored carefully as they are likely to deteriorate due to their underlying cancer. Figure 2 shows the associations between cancer, inflammation, pain, opioids and survival.

\section{Implications for research}

Large prospective cohort studies with the effect of opioids on survival as a primary outcome, where pain is known before and after opioids have started, is needed to understand the relationship between opioids and survival further. Careful depiction of the clinical situation, opioid dose, titration, and monitoring for individual patients is needed to further understand the relationship of opioids with clinical outcomes. As this exploratory analysis indicates systemic inflammation related to tumour activity might be a driver for increased pain, it is recommended that inflammatory markers (including CRP) should be measured.

\section{Conclusions}

This secondary data analysis of the EPCCS data set of adults with advanced, incurable cancer, showed an association of opioid-use with decreased survival, although causality cannot be determined. With a sensitivity analysis of a subset with
CRP measures, the relationship with opioid-use reduced. Tumour-related systemic inflammation could be the independent variable explaining the observed relationship with opioids. Further prospective study is needed to test this hypothesis and accurately judge the effects of opioids, pain and tumour-related inflammation in patients with advanced progressive disease.

\section{Acknowledgements}

\section{EPCCS description.}

The European Palliative Care Cancer Symptom study (EPCCS) is a collaborative effort between the European Palliative Care Research Centre (PRC), and the European Association for Palliative Care Research Network (EAPC-RN). EPCCS was partially funded by grant no. 6070 from the joint Research Council at Norwegian University of Science and Technology (NTNU) and St. Olavs Hospital-Trondheim University Hospital.

Project management:

Marianne J. Hjermstad PRC/NTNU; Stein Kaasa, PRC/NTNU/ EAPC-RN; Dagny F. Haugen, PRC/NTNU; Pål Klepstad PRC/ NTNU, and Gunnhild Jakobsen PRC/NTNU, Norway; Augusto Caraceni, PRC/EAPC-RN and Cinzia Brunelli, PRC/Italy; Per Sjøgren, EAPC-RN, Denmark; Florian Strasser, Switzerland; Barry Laird, PRC/UK.

Project steering committee.

Marianne J. Hjermstad PRC/NTNU and Stein Kaasa, PRC/NTNU/ EAPC-RN, Norway; Augusto Caraceni, PRC/EAPC-RN and Cinzia Brunelli, PRC/Italy; Per Sjøgren, EAPC-RN, Denmark, Luc Deliens EAPC-RN, Belgium, Mike Bennett; EAPC-RN, UK; David Currow; Australia, Vickie Baracos, Canada.

Core Centre collaborators, one from each site Erik Løhre, St. Olavs Hospital-Trondheim University Hospital; Nina Aass, Oslo University Hospital; Elisabeth Brenne, Øya Helsehus; and Inge Raknes, Haraldsplass Deaconess Hospital; Norway; Geana Kurita, Rigshospitalet and Mogens Groenvold, Bispebjerg Hospital, Denmark; Florian Strasser, Cantonal Hospital St. Gallen, and Cristian Camartin, Kantonspital, Graubünden, Switzerland; Alessandra Pigni, Fondazione IRCCS Istituto Nazionale dei Tumori, Luigi Cavanna, Oncologia Medica Ospedale Di PiacenzA; Adriana Turriziani, Hospice Villa Speranza Roma; Franco Rizzi, U.O. Complessa di Cure Palliative e Terapia del Dolore. AO ICP Milan; Laura Piva; Unità di Cure Palliative Azienda Ospedaliera San Paolo, Milan; Giampiero Porzio, Oncologia Medica Università degli Studi, L'Aquila; and Rondini 
Ermanno, U.O. Oncologia Medica Arcispedale S. Maria NuovaIRCCS, Reggio Emilia, Italy; Mike Bennett, Leeds Institute of Health Sciences/University of Leeds; Barry Laird, Western General Hospital Edinburgh/Beatson West of Scotland Cancer Centre; Edinburgh; Andrew Wilcock, Nottingham University Hospitals NHS Trust, Nottingham and Karen Harvie, Marie Curie Hospice, Glasgow, UK, Maria Nabal, Hospital Universitário Arnau de Vilanova Lleida, Antonio N. Tejedor, Hospital Centro de Cuidados Laguna, Madrid; Josep Porta Sales, Institut Català d'Oncologia, Barcelona; and Marina Martínez, Clinica Universidad De Navarra Pamplona; Spain; Konrad Fassbender, University of Alberta, Canada, David Currow, Flinders University, Australia; Nikolay Yordanov, Comprehensive Cancer Center Vratsa, Bulgaria; Koen Pardon, Ghent University Hospital Flanders, Belgium; Ioseb Abesadze, Cancer Prevention Center, Tblisi, Georgia Madalena Feio, Instituto Português de Oncologia Francisco Gentil Lisbon, Portugal.

Authors Contribution J.W.B.: Study design, interpretation of data, writing up of the first draft of the paper and article revision; V.A. Study design, data analysis, interpretation of data and article revision; E.B.: Study design, interpretation of data and article revision; M.I.B: Patient recruitment, data collection and article revision; S.K.: Study design of primary study, patient recruitment and data collection; M.H: Study design of primary study, patient recruitment and data collection; M.J: Study design, interpretation of data and article revision. All authors give final approval to this version of the manuscript to be published and agree to be accountable for it.

\section{Compliance with ethical standards}

Declaration of interests None of the authors declare any conflicts of interest.

Funding Central Norway Regional Health Authority (grant no. 46055100), The Cancer Foundation St Olavs Hospital, Norway, Trondheim University Hospital (grant no. 6070) and an unrestricted grant from the Helsinn group, Switzerland.

Open Access This article is licensed under a Creative Commons Attribution 4.0 International License, which permits use, sharing, adaptation, distribution and reproduction in any medium or format, as long as you give appropriate credit to the original author(s) and the source, provide a link to the Creative Commons licence, and indicate if changes were made. The images or other third party material in this article are included in the article's Creative Commons licence, unless indicated otherwise in a credit line to the material. If material is not included in the article's Creative Commons licence and your intended use is not permitted by statutory regulation or exceeds the permitted use, you will need to obtain permission directly from the copyright holder. To view a copy of this licence, visit http://creativecommons.org/licenses/by/4.0/.

\section{References}

1. Bouhassira D, Luporsi E, Krakowski I (2017) Prevalence and incidence of chronic pain with or without neuropathic characteristics in patients with cancer. Pain. 158(6):1118-1125. https://doi.org/10. 1097/j.pain.0000000000000895

2. Smith D, Wilkie R, Uthman O, Jordan JL, McBeth J (2014) Chronic pain and mortality: a systematic review. PLoS One 9(6): e99048. https://doi.org/10.1371/journal.pone.0099048
3. Halabi S, Vogelzang NJ, Kornblith AB, Ou SS, Kantoff PW, Dawson NA et al (2008) Pain predicts overall survival in men with metastatic castration-refractory prostate cancer. J Clin Oncol 26(15):2544-2549. https://doi.org/10.1200/JCO.2007.15.0367

4. Fizazi K, Massard C, Smith M, Rader M, Brown J, Milecki P, Shore N, Oudard S, Karsh L, Carducci M, Damião R, Wang H, Ying W, Goessl C (2015) Bone-related parameters are the Main prognostic factors for overall survival in men with bone metastases from castration-resistant prostate Cancer. Eur Urol 68(1):42-50. https:// doi.org/10.1016/j.eururo.2014.10.001

5. Oudard S, Banu E, Medioni J, Scotte F, Banu A, Levy E, Wasserman J, Kacso G, Andrieu JM (2009) What is the real impact of bone pain on survival in patients with metastatic hormonerefractory prostate cancer treated with docetaxel? BJU Int 103(12):1641-1646. https://doi.org/10.1111/j.1464-410X.2008. 08283.x

6. Zylla D, Steele G, Gupta P (2017) A systematic review of the impact of pain on overall survival in patients with cancer. Support Care Cancer 25(5):1687-1698. https://doi.org/10.1007/s00520017-3614-y

7. Ahmedzai SH, Boland J (2007) Opioids for chronic pain: molecular and genomic basis of actions and adverse effects. Curr Opin Support Palliat Care. 1(2):117-125. https://doi.org/10.1097/SPC. $0 \mathrm{~b} 013 \mathrm{e} 3282 \mathrm{f0} 4 \mathrm{e} 0 \mathrm{c}$

8. von Gunten CF (2016) The pendulum swings for opioid prescribing. J Palliat Med 19(4):348. https://doi.org/10.1089/jpm.2016. 0079

9. Boland JW, McWilliams K, Ahmedzai SH, Pockley AG (2014) Effects of opioids on immunologic parameters that are relevant to anti-tumour immune potential in patients with cancer: a systematic literature review. Br J Cancer 111(5):866-873. https://doi.org/10. 1038/bjc.2014.384

10. Boland JW, Pockley AG (2018) Influence of opioids on immune function in patients with cancer pain: from bench to bedside. Br J Pharmacol 175(14):2726-2736. https://doi.org/10.1111/bph.13903

11. Chang WP, Lin CC (2015) Use of opioid analgesics or sleeping medication and survival of cancer patients. Eur J Oncol Nurs 19(3):199-206. https://doi.org/10.1016/j.ejon.2014.11.007

12. Boland JW, Allgar V, Boland EG, Oviasu O, Agar M, Currow DC, Johnson MJ (2017) Effect of opioids and benzodiazepines on clinical outcomes in patients receiving palliative care: an exploratory analysis. J Palliat Med 20(11):1274-1279. https://doi.org/10.1089/ jpm.2017.0129

13. Zylla D, Steele G, Shapiro A, Richter S, Gupta P (2018) Impact of opioid use on health care utilization and survival in patients with newly diagnosed stage IV malignancies. Support Care Cancer 26(7):2259-2266. https://doi.org/10.1007/s00520-018-4062-z

14. Boland JW, Ziegler L, Boland EG, McDermid K, Bennett MI (2015) Is regular systemic opioid analgesia associated with shorter survival in adult patients with cancer? A systematic literature review. Pain. 156(11):2152-2163. https://doi.org/10.1097/j.pain. 0000000000000306

15. Minami S, Fujimoto K, Ogata Y, Yamamoto S, Komuta K (2015) Opioids have no negative effect on the survival time of patients with advanced lung cancer in an acute care hospital. Support Care Cancer 23(8):2245-2254. https://doi.org/10.1007/s00520-0142592-6

16. Sathornviriyapong A, Nagaviroj K, Anothaisintawee T (2016) The association between different opioid doses and the survival of advanced cancer patients receiving palliative care. BMC Palliat Care 15(1):95. https://doi.org/10.1186/s12904-016-0169-5

17. Hasegawa T, Oguri T, Osawa T, Sawa T, Osaga S, Okuyama T, Uchida M, Maeno K, Fukuda S, Nishie H, Niimi A, Akechi T (2018) Opioid dose and survival of patients with incurable nonsmall cell lung Cancer: a prospective cohort study. J Palliat Med 21(10): 1436-1441. https://doi.org/10.1089/jpm.2018.0044 
18. Roxburgh CS, McMillan DC (2014) Cancer and systemic inflammation: treat the tumour and treat the host. Br J Cancer 110(6): 1409-1412. https://doi.org/10.1038/bjc.2014.90

19. Laird BJ, McMillan DC, Fayers P, Fearon K, Kaasa S, Fallon MT, Klepstad P (2013) The systemic inflammatory response and its relationship to pain and other symptoms in advanced cancer. Oncologist. 18(9):1050-1055. https://doi.org/10.1634/ theoncologist.2013-0120

20. Al-Mazidi S, Farhat K, Nedjadi T, Chaudhary A, Zin Al-Abdin O, Rabah D et al. Association of Interleukin-6 and Other Cytokines with Self-Reported Pain in Prostate Cancer Patients Receiving Chemotherapy. Pain Med. 2017:doi: https://doi.org/10.1093/pm/ pnx145. [Epub ahead of print]. doi:https://doi.org/10.1093/pm/ pnx145

21. Ji YB, Bo CL, Xue XJ, Weng EM, Gao GC, Dai BB, Ding KW, Xu CP (2017) Association of Inflammatory Cytokines with the symptom cluster of pain, fatigue, depression, and sleep disturbance in Chinese patients with Cancer. J Pain Symptom Manag 54(6):843852. https://doi.org/10.1016/j.jpainsymman.2017.05.003

22. Laird BJ, Scott AC, Colvin LA, McKeon AL, Murray GD, Fearon KC, Fallon MT (2011) Cancer pain and its relationship to systemic inflammation: an exploratory study. Pain. 152(2):460-463. https:// doi.org/10.1016/j.pain.2010.10.035

23. Evers PD, Logan JE, Sills V, Chin AI (2014) Karnofsky performance status predicts overall survival, cancer-specific survival, and progression-free survival following radical cystectomy for urothelial carcinoma. World J Urol 32(2):385-391. https://doi.org/ 10.1007/s00345-013-1110-7

24. Ouyang H, Ma W, Liu F, Yue Z, Fang M, Quan M, Pan Z (2017) Factors influencing survival of patients with pancreatic adenocarcinoma and synchronous liver metastases receiving palliative care. Pancreatology. 17(5):773-781. https://doi.org/10.1016/j.pan.2017. 07.002

25. Chow E, Abdolell M, Panzarella T, Harris K, Bezjak A, Warde P, Tannock I (2008) Predictive model for survival in patients with advanced cancer. J Clin Oncol 26(36):5863-5869. https://doi.org/ 10.1200/JCO.2008.17.1363

26. Laird BJ, Kaasa S, McMillan DC, Fallon MT, Hjermstad MJ, Fayers P, Klepstad P (2013) Prognostic factors in patients with advanced cancer: a comparison of clinicopathological factors and the development of an inflammation-based prognostic system. Clin Cancer Res 19(19):5456-5464. https://doi.org/10.1158/1078-0432. CCR-13-1066

27. Hjermstad MJ, Aass N, Aielli F, Bennett M, Brunelli C, Caraceni A et al. Characteristics of the case mix, organisation and delivery in cancer palliative care: a challenge for good-quality research. BMJ Support Palliat Care. 2016:doi: https://doi.org/10.1136/bmjspcare2015-000997. [Epub ahead of print]. doi:https://doi.org/10.1136/ bmjspcare-2015-000997

28. Staplin ND, Kimber AC, Collett D, Roderick PJ (2015) Dependent censoring in piecewise exponential survival models. Stat Methods Med Res 24(3):325-341. https://doi.org/10.1177/ 0962280214544018

29. Ferrat E, Paillaud E, Laurent M, Le Thuaut A, Caillet P, Tournigand $\mathrm{C}$ et al (2015) Predictors of 1-year mortality in a prospective cohort of elderly patients with Cancer. J Gerontol A Biol Sci Med Sci 70(9):1148-1155. https://doi.org/10.1093/gerona/glv025
30. Quaresma M, Coleman MP, Rachet B (2015) 40-year trends in an index of survival for all cancers combined and survival adjusted for age and sex for each cancer in England and Wales, 1971-2011: a population-based study. Lancet. 385(9974):1206-1218. https://doi. org/10.1016/S0140-6736(14)61396-9

31. Ganly I, Nixon IJ, Wang LY, Palmer FL, Migliacci JC, Aniss A, Sywak M, Eskander AE, Freeman JL, Campbell MJ, Shen WT, Vaisman F, Momesso D, Corbo R, Vaisman M, Shaha A, Tuttle RM, Shah JP, Patel SG (2015) Survival from differentiated thyroid Cancer: what has age got to do with it? Thyroid : official journal of the American Thyroid Association 25(10):1106-1114. https://doi. org/10.1089/thy.2015.0104

32. Boland JW, Bennett MI (2016) Opioids do not influence metastasis in experimental animal cancer models. Pain. 157(5):1173. https:// doi.org/10.1097/j.pain.0000000000000463

33. Ahmedzai SH, Boland J (2007) The total challenge of cancer pain in supportive and palliative care. Curr Opin Support Palliat Care. 1(1):3-5. https://doi.org/10.1097/SPC.0b013e328151c401

34. Brown MR, Ramirez JD (2015) Neuroimmune mechanisms in cancer pain. Curr Opin Support Palliat Care 9(2):103-111. https://doi. org/10.1097/SPC.0000000000000140

35. Boland EG, Mulvey MR, Bennett MI (2015) Classification of neuropathic pain in cancer patients. Curr Opin Support Palliat Care. 9(2):112-115. https://doi.org/10.1097/SPC.0000000000000136

36. Amano K, Maeda I, Morita T, Miura T, Inoue S, Ikenaga M et al (2016) Clinical implications of C-reactive protein as a prognostic marker in advanced Cancer patients in palliative care settings. $\mathrm{J}$ Pain Symptom Manag 51(5):860-867. https://doi.org/10.1016/j. jpainsymman.2015.11.025

37. Kim YJ, Kim SJ, Lee JK, Choi WS, Park JH, Kim HJ, Sim SH, Lee KW, Lee SH, Kim JH, Kim DW, Lee JS, Bang YJ, Heo DS (2014) Prediction of survival in terminally ill cancer patients at the time of terminal cancer diagnosis. J Cancer Res Clin Oncol 140(9):15671574. https://doi.org/10.1007/s00432-014-1688-1

38. Higginson IJ, Gao W (2012) Opioid prescribing for cancer pain during the last 3 months of life: associated factors and 9-year trends in a nationwide United Kingdom cohort study. J Clin Oncol 30(35): 4373-4379. https://doi.org/10.1200/JCO.2012.42.0919

39. Gagnon B, Scott S, Nadeau L, Lawlor PG (2015) Patterns of community-based opioid prescriptions in people dying of cancer. J Pain Symptom Manag 49(1):36-44 e1. https://doi.org/10.1016/j. jpainsymman.2014.05.015

40. Ziegler L, Mulvey M, Blenkinsopp A, Petty D, Bennett MI (2016) Opioid prescribing for patients with cancer in the last year of life: a longitudinal population cohort study. Pain. 157(11):2445-2451. https://doi.org/10.1097/j.pain.0000000000000656

Data Deposition Information Including Weblink Data from the study is deposited at: The Unit for Applied Clinical Research, Faculty of Medicine and Health Sciences Norwegian University of Science and Technology (NTNU), Trondheim, Norway. https://www.ntnu.edu/mh/akf

Publisher's note Springer Nature remains neutral with regard to jurisdictional claims in published maps and institutional affiliations. 